\title{
Accelerated Bilateral Cataract Formation as a First Manifestation of Diabetes Mellitus
}

\section{Manaviat M. R. ${ }^{1}$, Oveisi N. ${ }^{1}$, Zare-Bidoki A. ${ }^{2}$}

${ }^{1}$ Department of Ophthalmology, Shahid Sadoughi Hospital, Shahid Sadoughi University of Medical Sciences and Health Services, Yazd, Iran;

${ }^{2}$ Shahid Sadoughi Hospital, Shahid Sadoughi University of Medical Sciences and Health Services, Yazd, Iran

Received August 28, 2013; Accepted November 25, 2013.

Key words: Bilateral cataract - Diabetes mellitus - Children

Abstract: There is a proved relationship between diabetes mellitus and the cataract formation. The incidence of this is usually related to the duration of diabetes. In this manuscript we report a 15 years old female presented to the emergency room with a 4 hour history of rapid bilateral diminished vision, initially diagnosed with idiopathic cataracts, but after more laboratory evaluations revealed new-onset type 1 diabetes mellitus without ketosis.

Mailing Address: Nasim Oveisi, MD., Department of Ophthalmology, Shahid Sadoughi Hospital, Ibn Sina BLVD, Ghandi BLVD, Safayieh, Yazd, Iran;

Phone: +983 518224 000; e-mail: nasimoveisi@yahoo.com 


\section{Case report}

15 years old female school student was admitted to the emergency ward with a sudden bilateral diminished vision that was developed within four hours (Figure 1). She had no previous visual complaints or any other diagnosed diseases. Her parents noticed perceptible complaints like increased weight, lack of energy, polydipsia, polyuria and polyphagia of their daughter during the previous month. The patient was of a full-term pregnancy, and there was no history of gestational diabetes mellitus (GDM) with the mother. She was delivered by caesarean section and birth weight was of $3.4 \mathrm{~kg}$. She had a family history of type 2 diabetes in both grandmothers and grandfathers. She also had no history of any surgical procedures, eye trauma, infection or exposure to radiation. However she had a history of mild hypothyroidism and mild asthma which was not treated by any medication by the patient and based on endocrinologist, her hypothyroidism was not a case of medication therapy. In the clinical examination, visual acuity was with hand motion bilaterally; both lenses were intumescent with dense cortical opacities. Fundus
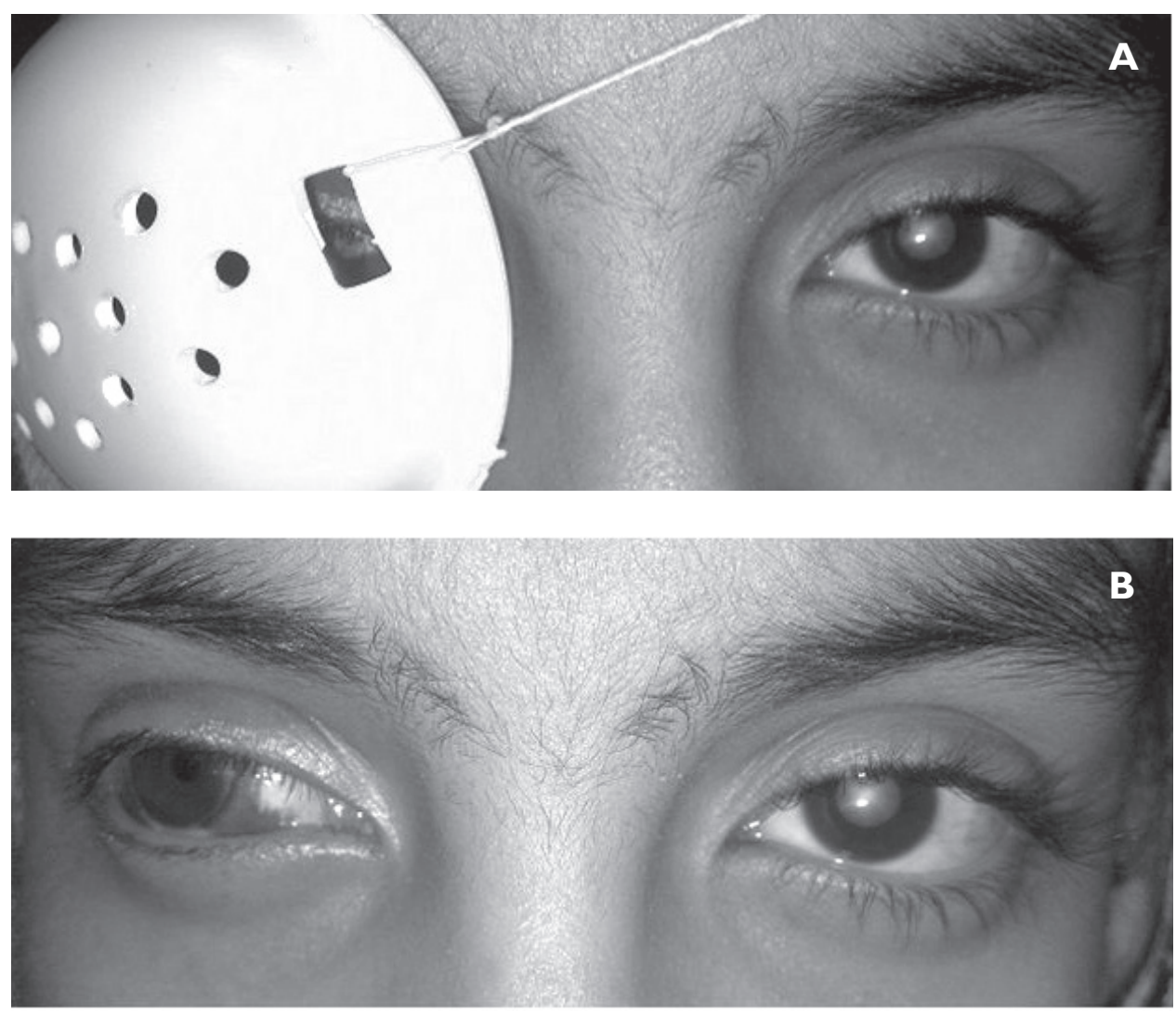

Figure 1 - Intumescent lens with dense cortical opacities (A and B). 
could not be visualized due to the presence of dense bilateral cortical cataracts. Blood pressure was $110 / 60 \mathrm{~mm} \mathrm{Hg}$, with a $37^{\circ} \mathrm{C}$ oral temperature. Weight was $40 \mathrm{~kg}$ with a body mass index (BMI) of 17 . There was no evidence of peripheral vascular disease or neuropathy. Results of initial laboratory test revealed fasting blood glucose (FBS) of $434 \mathrm{mg} / \mathrm{dl}$, blood glucose (BS) $619 \mathrm{mg} / \mathrm{dl}$, blood urea $27 \mathrm{mg} / \mathrm{dl}$, and one hour erythrocyte sedimentation rate (ESR) $22 \mathrm{~mm} / \mathrm{h}$. Glycosuria was detected in urinalysis (UA). Her HbA1c was $10.6 \%$. After normalization of glycaemic profile, her visual acuity improved so that she was able to count fingers at a one meter distance and then underwent successful cataract extraction in different sessions with complete restoration of vision. No evidence of retinopathy was found following surgery.

Currently the patient is controlled by insulin doses and her quality of life has improved greatly and her function at school is good.

\section{Discussion}

Cataract is defined as clouding or opacification of normally crystalline lens of the eye. Cataracts can occur earlier in life but its progress could accelerate more rapidly in presence of diabetes (Datta et al., 1997). From 1798, the year in which the first case of cataract in patients with insulin dependent diabetes mellitus (IDDM) was proposed, there have been many studies on the early development of cataract following IDDM (Malone, 1983-1985). Although there is a proven relation between IDDM and cataract, acute development of bilateral cataract after diagnosis of diabetes mellitus is rare and there are few studies reporting such situation (Cornwell and Lepre, 1995; Datta et al., 1997; Montgomery and Batch, 1998; Florkowski et al., 2005; Awan et al., 2006; Costagliola et al., 2007; Wilson et al., 2007; Pakhetra and Jyotsna, 2009). In this study we report a case of acute bilateral vision loss which is very rare condition and was reported in fewer studies.

A diabetic or metabolic cataract is determined by diffuse posterior and/or anterior sub capsular or cortical snowflakes opacities (Datta et al., 1997). This situation is followed by an appearance of more diffuse cloudiness and opacification. Such features indicate long duration of poor controlled IDDM that could be characterized by elevated HbA1c. Cataract is more prevalent in females and at adolescent age while IDDM is more prevalent in male (Ehrlich et al., 1987; Lang-Muritano et al., 1995). The most common presentation of IDDM in childhood is hyperglycemia without acidosis and presentations of hyperglycemia like polyuria, polydipsia, weight loss despite initial polyphagia and possibly lethargy is detected (Cooke and Plotnick, 2008). Cataract is an uncommon initial presentation of IDDM in children and it is necessary to rule out other underlying causes of cataract before surgery.

The exact pathogenesis is not yet well understood. It is possible that the duration of symptoms plays an effective role but is not the only factor as all patients will not develop cataract, and good control did not prevent complication 
in all patients (Falck and Laatikainen, 1998). One proposed pathogenesis is the effect of polyol pathway. In this pathway glucose is converted to sorbitol which accumulates in the lens, and induces a hyperosmotic effect causing infusion of fluid of the balance of osmotic gradient (Pollreisz and Schmidt-Erfurth, 2010). Possibly this osmotic stress triggers apoptosis in epithelial cells of the lens (Takamura et al., 2001) and develops into cataract. Another proposed pathogenesis is the induction of glycation in lens proteins following increased glucose levels in the aqueous humor. This process may lead to production of superoxide radicals (Stitt, 2005). Due to impaired antioxidant capacity in lens, it is susceptible to oxidative stress; this situation is exacerbated by glycation (Ookawara et al., 1992).

In our case there was a history of mild hypothyroidism which was not in need of treatment. But this mild hypothyroidism may have accelerated the progression of cataracts in this patient. We found only one report of partly similar accompaniment which reported a child with cataract that had diabetes mellitus and Hashimoto thyroiditis simultaneously (Alouf and Pascual, 1996). This article believes that hypothyroidism modified the symptoms of diabetes, resulting in atypical presentation.

There is only one other study which studied on 600 paediatric diabetic patients retrospectively and estimated prevalence of bilateral cataracts about $1 \%$ (6 in 600 studied patients) (Falck and Laatikainen, 1998).

It is recommended by the International Society for Pediatric and Adolescent Diabetes to do an initial ophthalmological examination in newly diagnosed IDDM children and adolescents aiming to detect cataract (Donaghue et al., 2009), especially in patients with poor metabolic control and/or symptoms of blurred vision this evaluation should be done promptly. Regular ophthalmological examination may begin by the fifth year of IDDM diagnosis or at the onset of puberty to detect ophthalmological complications of diabetes. Constant well maintained metabolic control is effective in prevention of ophthalmological complications including cataract.

\section{Conclusion}

In case of diabetic cataract in paediatric IDDM, early diagnosis and management is needed to restore healthy sight to the patient.

\section{References}

Alouf, B., Pascual, A. G. (1996) Cataracts as the presenting feature of diabetes mellitus in a child. Clin. Pediatr. (Phila.) 35, 37-39.

Awan, A., Saboor, T., Buchanan, L. M. (2006) Acute irreversible diabetic cataract in adolescence: a case report. Eye 20, 398-400.

Cooke, D. W., Plotnick, L. (2008) Type 1 diabetes mellitus in pediatrics. Pediatr. Rev. 29, 374-384.

Cornwell, M., Lepre, F. (1995) Acute irreversible cataracts in diabetes mellitus. Aust. N. Z. J. Ophthalmol. 23 , $221-222$. 
Costagliola, C., Dell'Omo, R., Prisco, F., lafusco, D., Landolfo, F., Parmeggiani, F. (2007) Bilateral isolated acute cataracts in three newly diagnosed insulin dependent diabetes mellitus young patients. Diabetes Res. Clin. Pract. 76, 313-315.

Datta, V., Swift, P. G., Woodruff, G. H., Harris, R. F. (1997) Metabolic cataracts in newly diagnosed diabetes. Arch. Dis. Child. 76, 118-120.

Donaghue, K. C., Chiarelli, F., Trotta, D., Allgrove, J., Dahl-Jorgensen, K. (2009) Microvascular and macrovascular complications associated with diabetes in children and adolescents. Pediatr. Diabetes 10, 195-203.

Ehrlich, R. M., Kirsch, S., Daneman, D. (1987) Cataracts in children with diabetes mellitus. Diabetes Care 10, 798-799.

Falck, A., Laatikainen, L. (1998) Diabetic cataract in children. Acta Ophthalmol. Scand. 76, 238-240.

Florkowski, A. R., Golden, R., Sooch, Y., Krishna, R. (2005) Sudden bilateral visual loss in a diabetic man. Am. J. Med. Sci. 329, 99-101.

Lang-Muritano, M., La Roche, G. R., Stevens, J. L., Gloor, B. R., Schoenle, E. J. (1995) Acute cataracts in newly diagnosed IDDM in five children and adolescents. Diabetes Care 18, 1395-1396.

Malone, J. I. (1983-1985) Ophthalmologic complications of insulin-dependent diabetes mellitus in children and adolescents. Pediatrician 12, 194-198.

Montgomery, E. L., Batch, J. A. (1998) Cataracts in insulin-dependent diabetes mellitus: Sixteen years' experience in children and adolescents. J. Paediatr. Child Health 34, 179-182.

Ookawara, T., Kawamura, N., Kitagawa, Y., Taniguchi, N. (1992) Site-specific and random fragmentation of Cu, $\mathrm{Zn}$-superoxide dismutase by glycation reaction. Implication of reactive oxygen species. J. Biol. Chem. 267, 18505-18510.

Pakhetra, L. C. R., Jyotsna, V. P. (2009) Bilateral early cataracts in type 1 diabetes. MJAFI 65, 71-72.

Pollreisz, A., Schmidt-Erfurth, U. (2010) Diabetic cataract-pathogenesis, epidemiology and treatment. J. Ophthalmol. 2010, 608751.

Stitt, A. W. (2005) The maillard reaction in eye diseases. Ann. N. Y. Acad. Sci. 1043, 582-597.

Takamura, Y., Sugimoto, Y., Kubo, E., Takahashi, Y., Akagi, Y. (2001) Immunohistochemical study of apoptosis of lens epithelial cells in human and diabetic rat cataracts. Jpn. J. Ophthalmol. 45, 559-563.

Wilson, M. E. Jr., Levin, A. V., Trivedi, R. H., Kruger, S. J., Elliott, L. A., Ainsworth, J. R., Awner, S., Cruz, O. A., Kivlin, J., Vroman, D. T., Young, W. O. (2007) Cataract associated with type-1 diabetes mellitus in the pediatric population.J. AAPOS 11, 162-165. 